\title{
Spectrum of tumour and tumour-like lesions of bone in a Tertiary Care Hospital in North Karnataka, India
}

\author{
Gayathri T.,", , Shashikala V. ${ }^{2}$, Sody Rekha ${ }^{3}$ \\ ${ }^{1}$ Assistant Professor, ${ }^{2,3}$ Associate Professor, Dept. of Pathology, Vydehi Institute of Medical Sciences, Bengaluru,
} Karnataka, India

*Corresponding Author:

Email: Gayathri.bellary@gmail.com

\begin{abstract}
s
Introduction: The wide spectrum of bone tumours, their diverse origin and the tendency of these tumors to produce overlapping anatomic patterns, make osseous neoplasms a complicated but highly challenging area from the point of view of morphological diagnosis.

Objectives: To know the pattern of tumour and tumour-like lesions of bone including their incidence, age, sex and anatomical distribution, histo-morphological features in a tertiary care hospital of South India.

Materials and Methods: Biopsies and specimens received at the department of Pathology, Karnataka Institute of Medical Sciences, Hubli from July 2006 to June 2011 (5 year period) are included in the study.

Results: A total of 115 cases were included in the study of which $104(90.4 \%)$ were tumors of bone and $11(9.6 \%)$ were tumor-like lesions. Primary bone tumors were seen in $101(97.1 \%)$ cases and secondary tumors were seen in 3 cases $(2.9 \%)$.

Out of all lesions studied, malignant bone tumours were 31 (26.9\%), benign bone tumours $71(61.73 \%)$ and tumour like lesions $13(11.3 \%)$.

Osteochondroma $(50.7 \%)$ was most common benign tumor followed by osteoclastoma (40.8\%). Osteosarcoma was commonest malignant tumor (58\%) followed by Ewing's sarcoma (16.2\%). There were 3 cases of secondary tumors- one of renal cell carcinoma and the other two were adenocarcinomas of unknown primary.

Conclusion: This study showed that benign tumours accounted for most of the primary bone tumours. Osteochondroma and osteosarcoma are the most common benign and primary malignant bone tumors, respectively.
\end{abstract}

Keywords: Bone tumours, Giant cell tumour, Histopathology, Osteosarcoma, Osteochondroma.

Received: $09^{\text {th }}$ July, 2017

Accepted: $21^{\text {st }}$ August, 2017

\section{Introduction}

Bone tumours are diverse in size, gross and histologic features and range in their biologic potential from the innocuous to the rapidly fatal. ${ }^{1}$ This diversity makes it critical to diagnose tumours correctly, stage them accurately and treat them appropriately, so that the patients can not only survive, but also maintain optimal function of the attached body parts. ${ }^{1}$ The wide spectrum of these tumours, their diverse origin from the multiple cell types found in bones coupled with the tendency of these tumours to produce overlapping anatomic patterns, make osseous neoplasms a complicated but highly challenging area from the point of view of morphological diagnosis. ${ }^{2}$

Though bone tumours are infrequently encountered compared to the occurrence of other neoplastic lesions, they are of great significance because majority of them affect adolescents and young adults with a tendency of aggressive course. $^{3}$ These tumours can prove to be most lethal with extensive metastasis. Many tumour like lesions present as neoplastic conditions clinically as well as on radiologic examination. Morphological diagnosis of bone tumour and tumour like lesions is highly challenging which has to have collateral data of clinical and radiological features. ${ }^{2}$ A proper histopathological diagnosis is useful in confirming the diagnosis and helps in staging the tumor and aid the surgeon in planning limb salvage surgery for early malignant and benign bone lesions. ${ }^{4}$

Bone tumours are comparatively uncommon among the wide array of human neoplasms. This has contributed to the paucity of meaningful data on incidence rates and limited information is provided by regional centres regarding relative frequency of cases on histological confirmation.

The present study was undertaken for understanding the frequency of occurrence of different bone tumours at KIMS, their clinical presentations, radiological appearances and morphological heterogeneity over a period of 5 years. 


\section{Materials and Methods}

This is a retrospective study conducted in the Department of Pathology (histopathology section) at Karnataka Institute of Medical Sciences, Hubli covering a period of 5 years from July 2006-June 2011. Histopathology slides, laboratory request forms from the case files along with clinical case sheets from medical records department were taken to study various bone tumours and tumour like lesions pertaining to this period. These were reviewed to provide relevant information on age, sex, histopathological interpretation, and the anatomical site of occurrence. Data tabulation and analysis was done to know the relative frequency of all observed parameters.

\section{Results}

Out of 115 lesions studied, malignant bone tumours were $31(26.9 \%)$, benign bone tumours $71(61.73 \%)$, and tumour like lesions $13(11.3 \%)$ as shown in Table 1.

Table 1: Showing classification of bone lesions based on Behaviour \& origin in the present study

\begin{tabular}{|l|l|l|l|}
\hline & \multicolumn{1}{|c|}{ Primary } & \multicolumn{1}{c|}{ Secondary } & \multicolumn{1}{c|}{ Total } \\
\hline Malignant & $28(25 \%)$ & $3(100 \%)$ & $31(26.95 \%)$ \\
\hline Benign & $71(63.3 \%)$ & -- & $71(61.73 \%)$ \\
\hline $\begin{array}{l}\text { Tumour like } \\
\text { Lesions }\end{array}$ & $13(11.6 \%)$ & -- & $13(11.3 \%)$ \\
\hline Total & $112(97.3 \%)$ & $3(2.6 \%)$ & 115 \\
\hline
\end{tabular}

The ratio of benign to malignant bone tumours was 2.29:1

All bone tumours and tumour like lesions from the present study are categorised according to the WHO histological classification of tumours.

Out of 115 lesions there were $20(17.3 \%)$ bone forming tumours, $42(36.5 \%)$ cartilage forming tumours, $30(26 \%)$ giant cell tumours, $5(4.34 \%)$ marrow tumours, $1(0.86 \%)$ vascular tumour, 3 $(2.6 \%)$ metastatic deposits and $13(11.3 \%)$ tumour like lesions as shown in tables 2, 3 and 4.

Table 2: Showing histological classification of Benign bone tumours in the present study

\begin{tabular}{|l|l|c|c|}
\hline Histological lesion & Benign tumours & N & \% \\
\hline Osteogenic tumours & Osteoma & 02 & 2.81 \\
\hline Cartilagenous tumours & Osteochondroma & 36 & 50.70 \\
& Enchondroma & 01 & 1.40 \\
& Chondroblastoma & 02 & 2.81 \\
\hline Giant & & 29 & 40.84 \\
cell tumours & & & \\
\hline Vascular & Cavernous hemangioma & 1 & 1.40 \\
\hline Total & & 71 & \\
\hline
\end{tabular}

Table 3: Table showing histological classification of malignant bone tumours in the present study

\begin{tabular}{|l|l|c|c|}
\hline \multicolumn{1}{|c|}{ Histological lesion } & \multicolumn{1}{c|}{ Malignant tumours } & N & \% \\
\hline Osteogenic tumours & Osteosarcoma (conventional) & 16 & 53.33 \\
& & & \\
& Telangectatic osteosarcoma & 02 & 6.66 \\
\hline Cartilagenous tumours & Chondrosarcoma & 03 & 10 \\
\hline Giant & & 1 & 3.33 \\
cell tumours & & 05 & 16.1 \\
\hline Ewing's sarcoma/PNET & Ewing's sarcoma & 01 & 3.33 \\
Plasma cell tumours & Plasmacytoma & 03 & 10 \\
\hline Metastatic deposits & & 31 & \\
\hline Total & & & \\
\hline
\end{tabular}

Table 4: Showing histological classification of Tumour- like lesions of bone in the present study

\begin{tabular}{|c|c|c|}
\hline Tumour like lesions & $\mathbf{N}$ & \% \\
\hline Simple bone cyst & 2 & 15.3 \\
\hline
\end{tabular}




\begin{tabular}{|l|c|c|}
\hline Aneurysmal bone cyst & 6 & 46.15 \\
\hline Non - ossifying fibroma & 1 & 7.69 \\
\hline Fibrous dysplasia & 2 & 15.38 \\
\hline Ossifying fibroma & 2 & 15.38 \\
\hline Total & 13 & \\
\hline
\end{tabular}

The age distribution of all bone tumour and tumour like lesions in the present study shows that a maximum of $40(34.78 \%)$ were in the $20-29$ years age group followed by $32(27.86 \%)$ in $10-19$ years as shown in table 5 .

Table 5: Showing Age and Gender distribution of all bone tumours and tumour-like lesions in the present study

\begin{tabular}{|l|c|c|c|}
\hline \multirow{2}{*}{ Age group in years } & \multicolumn{3}{|c|}{ Bone tumours $(\mathbf{n = 1 1 5})$} \\
\cline { 2 - 4 } & Males & Females & Total \& \% \\
\hline $0-9$ & 06 & 07 & $13(11.30)$ \\
\hline $10-19$ & 22 & 10 & $32(27.86)$ \\
\hline $20-29$ & 27 & 13 & $40(34.78)$ \\
\hline $30-39$ & 09 & 10 & $19(16.52)$ \\
\hline $40-49$ & 02 & 03 & $5(4.34)$ \\
\hline $50-59$ & 02 & 01 & $3(2.60)$ \\
\hline$>60$ & 02 & 01 & $3(2.60)$ \\
\hline Total & 70 & 45 & 115 \\
\hline
\end{tabular}

In the present study there were $70(60.8 \%)$ males and $45(39.2 \%)$ females. Male to female ratio was $1.5: 1$

Out of 104 neoplastic tumors, the most common benign and malignant tumors were osteochondroma $36(34.61 \%)$ and osteosarcoma $30(28.8 \%)$ respectively. The most common tumour-like lesion was aneurysmal bone cyst 6(5.21\%). Primary bone tumors were seen in 101 $(97.1 \%)$ cases and secondary tumors were seen in 3 cases $(2.9 \%)$. Among the benign tumours, osteochondroma was seen in $50.7 \%$, osteoclastoma in $42.2 \%$, osteoma and chondroblastoma in $2.8 \%$ each, enchondroma and cavernous hemangioma in $1.4 \%$ each. Out of 31 malignant tumours, osteosarcoma was seen in $58.1 \%$, Ewing's sarcoma in $12.9 \%$, chondrosarcoma and metastatic deposits in $9.6 \%$, plasmacytoma in $3.2 \%$ of cases. There were 3 cases of secondary tumors- one of renal cell carcinoma (Fig. 5) and the other two were adenocarcinomas of unknown primary.

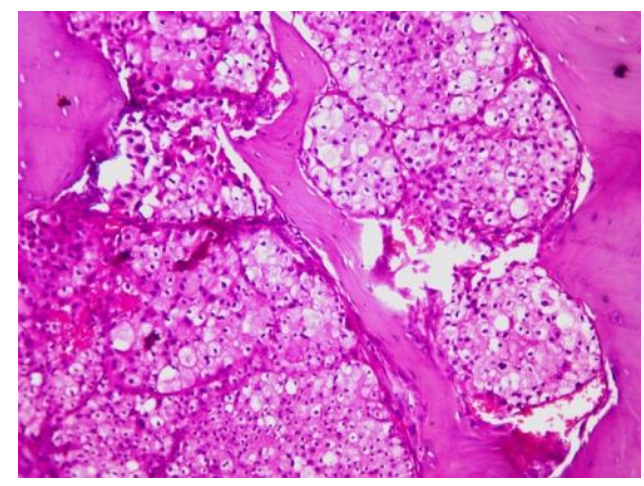

Fig. 5: Secondary deposits of renal cell carcinoma in bone (H\&E stain, 10x)

Out of $13(11.3 \%)$ tumor-like lesions, aneurysmal bone cyst was seen in $46.1 \%$, fibrous dysplasia, simple bone cyst and ossifying fibroma in $15.3 \%$ each, and non-ossifying fibroma in $7.7 \%$ of the cases.

\section{Discussion}

This retrospective study was done to study the spectrum and relative frequency of various bone lesions. The study was carried out by reassessing all the slides of received bone specimens that were sent to Pathology Department, KIMS, Hubli for the study period.

In the present study, benign bone tumours were more commonly encountered constituting $61.73 \%$ and malignant bone tumours were $26.9 \%$ among all bone lesions. The benign to malignant ratio was 2.29:1. This was in contrast to the 
observations made by some studies ${ }^{5,6,7}$ but is in conformity with other studies. ${ }^{4,8,9}$

The proportion of tumour like lesions in study reported in our study is $11.3 \%$ which is similar to Nayar M (10.9\%) and less compared to Chitale AR (22.9\%). , $^{5,6}$

Majority of the tumours in our study occurred in the $3^{\text {rd }}$ decade of life constituting $34.7 \%$. Similar findings in age incidence were also reported in other studies. ${ }^{4,10-12 .}$

Primary malignant bone tumors were more common than metastatic tumors which are in conformity with other studies ${ }^{10,13-16}$ whereas, the reverse is true for studies done by Gomez et al. ${ }^{17}$ This may be due to lack of access to diagnostic tests in advanced cancers due to poverty, old age, etc.

Osteochondroma was the most common benign tumour with male preponderance. Most of the patients fell within 11-20 years of age and long bones were commonly involved (Fig. 1 \& 2 ). This corresponds to study done by others. ${ }^{8,9}$, $11,12,13,15,16,17,18$. However, in a study conducted by Settakom et al., ${ }^{10}$ giant cell tumor was found to be the commonest benign bone tumor.

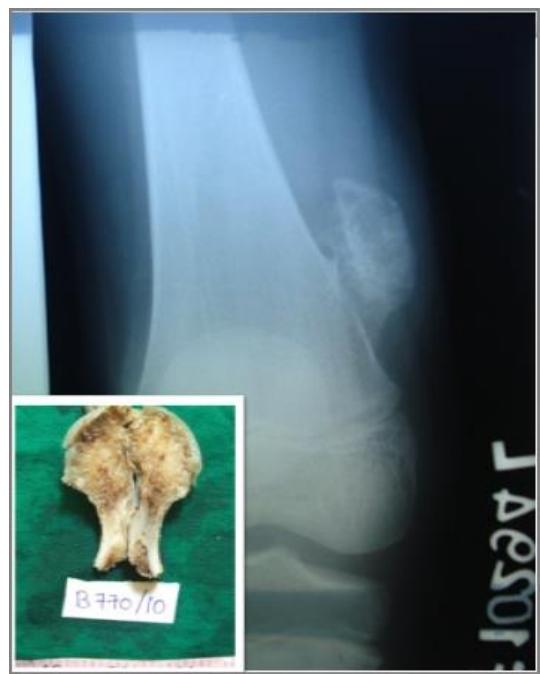

Fig. 1: X-ray and gross photographs of a pedunculated osteochondroma

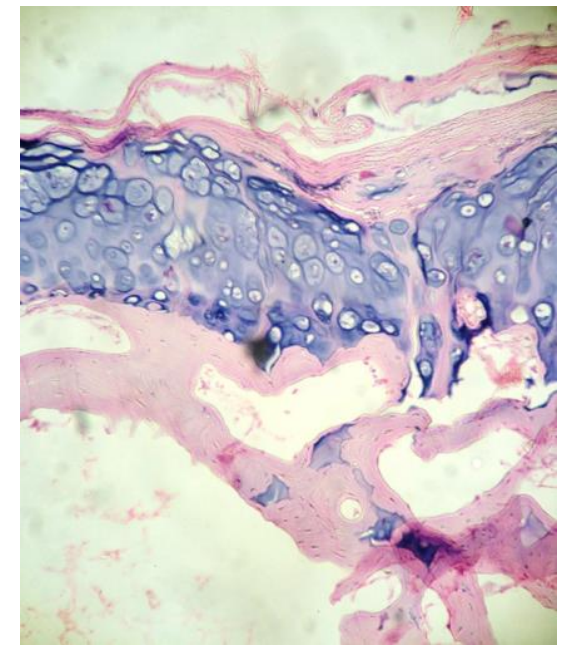

Fig. 2: Osteochondroma showing a fibrous capsule, cartilagenous cap and underlying bony trabeculae (H\&E stain, 4x)

Giant cell tumors made up thirty $(28.8 \%)$ of the total bone tumors (Fig. 3). Patients were mostly 20-50 years of age. These findings were in agreement with the study done by others. ${ }^{9,11}$. Our study showed no sex predilection which is in contrast with most studies which show a female preponderance. ${ }^{9,} 11$.

The most common malignant bone tumor was osteosarcoma $18(58 \%)$ of the 31 malignancies. Male preponderance was seen and long bones were commonly involved (Fig. 4). Similar findings were observed in other studies. ${ }^{9}$ $11,13,14,16,17,19-23$ While in the study by Yeole B B, Ewing's sarcoma was the commonest $(40.5 \%) .{ }^{24}$

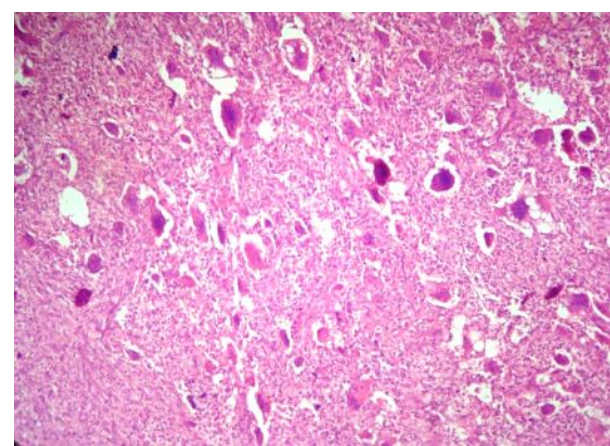

Fig. 3: Osteoclastoma showing giant cells and mononuclear cells $(H \& E$ stain, 10x) 


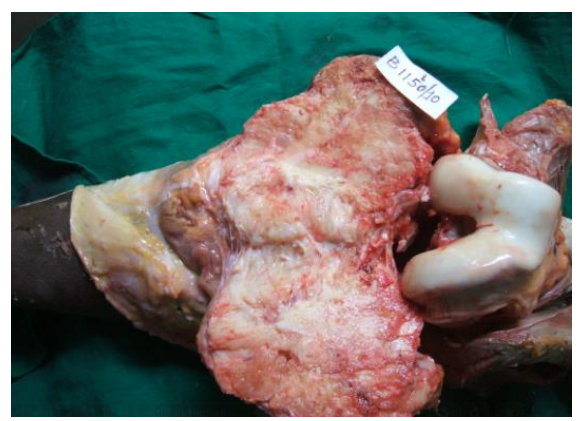

Fig. 4: Gross photograph of osteosarcoma in the upper tibial metaphysis with grey white, firm to hard mass with bone formation

We had two cases of osteosarcoma involving alveolar process of left maxilla and left inferior turbinate respectively which are rare sites according to Resnik. ${ }^{25}$

The present study has encountered 2 $(11.1 \%)$ cases of telangiectatic osteosarcomaone located in the upper tibia and the other in the diaphysis of radius. Huvos AG et al has reported an incidence of $11 \%$ which is similar to our study while Matsuno $\mathrm{T}$ et al have reported $2.6 \%$. 26,27

In the present study there were 3 cases of chondrosarcomas forming $9.6 \%$ of all malignant bone tumours. The incidence of chondrosarcomas among all bone sarcomas was similar to the observation by Nayar M (7.8\%) and Chitale AR (11.4\%).,6 Femur was the commonest site according to various studies. 5,6 In contrast the 3 cases in the present study were located one each in vertebral body (T9) (33.3\%), left $6^{\text {th }}$ rib $(33.3 \%)$ and metatarsal $(33.3 \%)$. Henderson et al have reported an incidence of $7.3 \%$ in spine, $17.3 \%$ in ribs and $2.08 \%$ in bones of hands and feet. ${ }^{28}$

In the present study there were 5 cases of Ewing's sarcoma constituting $16.12 \%$ of all primary malignant bone tumours. The incidence, male preponderance, commonest bones to be affected (femur and tibia) were similar to other studies. ${ }^{5,6}$ Majority of our cases were seen in $1^{\text {st }}$ decade where as $2^{\text {nd }}$ decade was commonest in other studies. ${ }^{5,6}$

Among tumour like lesions, we encountered six cases of aneurysmal bone cyst which is the commonest in our study. This is in contrast with few studies which found fibrous dysplasia to be the commonest. ${ }^{8} 9$

\section{Conclusion}

The present series summarizes the data available on 115 bone tumours and tumour-like lesions from a single health care center in terms of the tumor subtype, frequency, site of occurrence and patient demographics.The pathology department (histopathological section) has reported spectrum of 15 different types of histopathological bone tumours during the study period of 5 years which indicate the presence of different types of bone tumors in KIMS hospital and North Karnataka in general. Specific tumour has predilection for certain age, sex and site which are in conformity with our study from the data reviewed. Lastly, an exact diagnosis of bone tumours is at times difficult. Therefore, an integrated use of clinical, radiological, and histopathological finding is recommended to increase accuracy of diagnosis and for better management of the patient.

\section{References}

1. Mirra JM. Bone tumors: Diagnosis and treatment. Philadelphia: Lea Febiger;1989

2. Jaffe LH. Tumors \& Tumorous conditions of the Bones \& Joints. Lea \& Febiger. Philadelphia

3. Athanasou NA \& Woods CG. Locomotor system. In Mc Gee JD, Isacson PG \& Wright NA, editors. Oxford text book of Pathology. Oxford: Oxford university press; 1992. p.2047-72

4. Negash BE, Admasie D, Wamisho BL, Tinsay MW. Bone tumors at Addis Ababa University, Ethopia: Agreement between radiological and histopathological diagnosis- a 5-year analysis at Black-Lion Teaching Hospital. Malawi Med J 2009;1:62-5.

5. Chitale AR \& Jambhekar NA. Report of bone registry: 1970-1982 (12 year study). Indian Journal of Pathology \& Microbiology. 1987; 30: 201-218

6. Nayar M., 1979 "Bone tumors and tumor-like conditions- A retrospective study". Ind J Cancer, 16: $18-25$

7. Rhutso Y, Laishram RS, Sharma L D, Debnath K. Histopathological evaluation of bone tumors in a tertiary care hospital in Manipur, India. J Med Soc 2013;27:135-9

8. Mohammed A, Sani MA, Hezekiah IA, Enoch AA. Primary bone tumor and tumor like lesions in children in Zaria, Nigeria. Afr J Paediatr Surg 2010;7:16-8.

9. Mohammed A, Isa HA. Pattern of primary tumor and tumor like lesions of bone in Zaria, Northern Nigeria: A review of 127 cases. West Afr J Med 2007;26:37-41.

10. Baena-Ocampo Ldel C, Ramerez-Perez E, Linares-Gonzalez LM, Delgado Cheavez R. Epidemiology of bone tumors in Mexico City: Retrospective clinicopathologic study of 566 patients at a referral institution. Ann Diagn Pathol 2009;13:16-21.

11. Rao VS, Pai MR, Rao RC, Adhikary MM. Incidence of primary bone tumor and tumor like lesions in and around Dakshina Kannada district of Karnataka. J Indian Med Assoc 1996;94:103-4.

12. Sarma NH, al-Fituri O, Visweswara RN, Saeed SO. Primary bone tumor in eastern Libya- a 10 year study. Cent Afr J Med 1994;40:148-51. 
13. Settakom J, Lekawanvijit S, Arpornchayanon O, Rangdaeng S, Vanitanakom P, Kongkarnka S, et al. Spectrum of bone tumors in Chiang Mai University Hospital, Thailand according to WHO Classification 2002: A study of 1,001 cases. J Med Assoc Thai 2006;89:780-7

14. Rehman A, Qureshi H, Shafiullah. Bone tumors and tumor-like lesions: 10 years retrospective analysis of biopsy results. J Postgrad Med 2004;18:40-5.

15. Baena-Ocampo Ldel C, Ramerez-Perez E, Linares-Gonzalez LM, Delgado Cheavez R. Epidemiology of bone tumors in Mexico City: Retrospective clinicopathologic study of 566 patients at a referral institution. Ann Diagn Pathol 2009;13:16-21.

16. Shah SH, Muzaffar S, Soomro IN, Pervez S, Hasan SH. Clinicomorphological pattern and frequency of bone cancer. J Pak Med Assoc 1999;49:110-2.

17. Katchy KC, Ziad F, Alexander S, Gad H, Abdel Mota ál M. Malignant bone tumors in Kuwait: A 10 year clinicopathological study. Int Orthop 2005;29:406-11.

18. Pongkripetch M, Sirikulchayanonta V. Analysis of bone tumors in Ramathibodi Hospital, Thailand during 1977-86: A study of 652 cases. J Med Asso Thai 1989;72:621-8.

19. Valdespino-Gomez VM, Cintra-McGlone EA, Figueroa-Beltrán MA. Bone tumors: Their prevalence. Gac Med Mex 1990;126:325-34.

20. Estrada-Villasenor E, Delgado Cedillo EA, Rico Martinez G. Frequency of bone neoplasm in children. Acta Ortop Mex 2008;22:238-42.

21. Stiller CA, Bielack SS, Jundt G, SteliarovaFoucher E. Bone tumor in European children and adolescent 1978-1997. Report from Automated Childhood Cancer Information System Project. Eur J Caner 2006;42:2124-35.

22. Balubeck J, Atangana R, Eyenga V, Pison A, Sando Z, Hoffmeyer P. Bone tumor in Cameroon: Incidence, demography and histopathology. Int Orthop 2003;27:315-7.

23. Omololu S, Ogunbiji JO, Ogunlade SO, Alonge TO, Adebisi A, Akang EE. Primary malignant bone tumor in a tropical African teaching university. West Afr J Med 2002;21:291-3.

24. Blackwell JB, Threefall TJ, Mc Cavl RA. Primary malignant bone tumor in Western Australia 19721996. Pathology 2005;37:278-83.

25. Yeole B B and Jussawlla, 1998 " Descriptive epidemiology of bone cancer in greater Bombay" Ind $\mathrm{J}$ cancer, 35:101-106.

26. Resnick D, Kyriakos M and Greenway GD. Tumors and tumor-like lesions of bone: Imaging and pathology. In Resnick D, editor. Diagnosis of Bone and Joint disorders. $3^{\text {rd }}$ edn. Philadelphia: WB Saunders company; 1994

27. Huvos AG, Rosen G, Bretsky SS et al. Telangeictatic osteosarcoma: A Clinico pathological study of 124 patients. Cancer. 1982;49:1679-89.

28. Unni KK, Matsuno T, McLeod RA et al. Telangiectatic osteogenic sarcoma. Cancer. 1976; $38: 2538$

29. Henderson ED \& Dahlin DC. Chondrosarcoma of bone: A study of 288 cases. J Bone Joint Surg [Am]. 1963;45:1450. 